Article

\title{
Synthesis and Characterization of the New Dicyanamide $\mathrm{LiCs}_{2}\left[\mathrm{~N}(\mathrm{CN})_{2}\right]_{3}$
}

\author{
Markus Mann, Olaf Reckeweg ${ }^{(D)}$ and Richard Dronskowski *(D) \\ Chair of Solid-State and Quantum Chemistry, Institute of Inorganic Chemistry, RWTH Aachen University, \\ D-52056 Aachen, Germany; markus.mann@ac.rwth-aachen.de (M.M.); olaf.reykjavik@gmx.de (O.R.) \\ * Correspondence: drons@HAL9000.ac.rwth-aachen.de; Tel.: +49-241-80-93642; Fax: +49-241-80-92642
}

Received: 5 September 2018; Accepted: 2 October 2018; Published: 5 October 2018

check for updates

\begin{abstract}
Crystals of $\mathrm{LiCs}_{2}\left[\mathrm{~N}(\mathrm{CN})_{2}\right]_{3}$ were obtained from the reaction of stoichiometric amounts of aqueous solutions of $\mathrm{LiCl}$ and $\mathrm{CsBr}$ with $\mathrm{Ag}\left[\mathrm{N}(\mathrm{CN})_{2}\right]$. X-ray single-crystal structure analysis showed that $\mathrm{LiCs}_{2}\left[\mathrm{~N}(\mathrm{CN})_{2}\right]_{3}$ crystallizes isotypically to $\mathrm{NaCs}_{2}\left[\mathrm{~N}(\mathrm{CN})_{2}\right]_{3}$ and adopts the hexagonal space group $P 6_{3} / m$ (No. 176), with $a=6.8480(8), c=14.1665(17) \AA$, and $Z=2$. The IR and Raman spectra of the title compound exhibit modes typical for the dicyanamide anion.
\end{abstract}

Keywords: dicyanamide; lithium; cesium; structure elucidation; vibrational spectra

\section{Introduction}

Nitrogen-based materials are interesting not only for research purposes but also for industrial applications. Whether used as fertilizers, high-performance steel coatings, or lithium-ion battery materials [1,2], the research on nitrogen compounds has advanced and recently focused on complex nitrogen-containing compounds opposed to simple nitrides [3]. One interesting inorganic moiety is the boomerang-shaped dicyanamide anion $\left[\mathrm{N}(\mathrm{CN})_{2}\right]^{-}$which is often dubbed as [dca] $]^{-}$. This [dca] species has been found to allow for a rich diversity of compounds, simply due to its chemical stability as well as its ability to coordinate metal ions through terminal and/or bridging nitrogen atoms. Whenever coordination with all three nitrogen atoms of the [dca] anion occurs, ferromagnetic and antiferromagnetic transition-metal compounds with a rutile-like structure result [4]. On the other hand, [dca $^{-}$also forms one-dimensional (1D)- and two-dimensional (2D)-structures, which makes this anion interesting for crystal engineering [5]. Moreover, some dicyanamides show promise as water-oxidation catalysts [6], whilst Li[dca] has been suggested as a potential lithium-ion battery material [7]. In total, there is an enormous variety of pseudo-binary dicyanamide compounds available with examples known for ammonium [8], alkali metals [9-12], alkaline-earth metals [13], transition metals [4-6,14-19], and rare-earth metals [20-22]. Additionally, a number of pseudo-ternary dicyanamides has also been reported with $\mathrm{KCs}[\mathrm{dca}]_{2}$ [23], $\mathrm{LiK}[\mathrm{dca}]_{2}$ [24], $\left.\mathrm{LiRb}_{\mathrm{dca}}\right]_{2}$ [24], $\mathrm{NaRb}_{2}[\mathrm{dca}]_{3} \cdot \mathrm{H}_{2} \mathrm{O}$ [23], and $\mathrm{NaCs}_{2}[\mathrm{dca}]_{3}$ [25]. We here report the synthesis and single-crystal structure determination of the new pseudo-ternary compound $\mathrm{LiCs}_{2}[\mathrm{dca}]_{3}$ according to its IR and Raman spectra.

\section{Results and Discussion}

\subsection{Structural Description and Discussion}

$\mathrm{LiCs}_{2}[\mathrm{dca}]_{3}$ crystallizes isotypically to $\mathrm{NaCs}_{2}[\mathrm{dca}]_{3}$ [25] in the hexagonal space group $P 6_{3} / \mathrm{m}$ (No. 176) with $a=6.8480(4), c=14.1665(17) \AA$, and $Z=2$. The lattice parameters of $\mathrm{LiCs}_{2}[\mathrm{dca}]_{3}$ are smaller than those of $\mathrm{NaCs}_{2}[\mathrm{dca}]_{3}(a=7.0001(4), c=14.4929(7) \AA)$ due to the smaller cationic size of lithium compared to sodium. The boomerang-shaped dicyanamide anion exhibits bond lengths and angles consistent with those given in the literature: the bond length of $d(\mathrm{C}-\mathrm{N} 1)=1.16 \AA$ of the terminal 
C-N pairs indicates a triple bond, while the central C-N pairing with $d(\mathrm{C}-\mathrm{N} 2)=1.31 \AA$ is found to be in the expected distance range of a $\mathrm{C}-\mathrm{N}$ single bond. The angles of the [dca] anion are also typically found for such a moiety with $\measuredangle(\mathrm{N} 1-\mathrm{C}-\mathrm{N} 2)=172.1^{\circ}$ and $\measuredangle(\mathrm{C}-\mathrm{N} 1-\mathrm{C})=119.8^{\circ}$ (Figure 1, Table 1 ).

a)

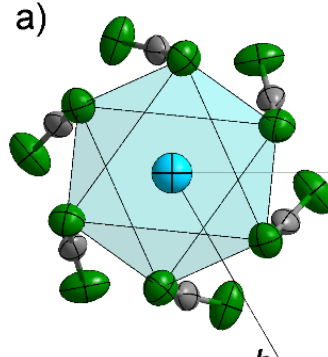

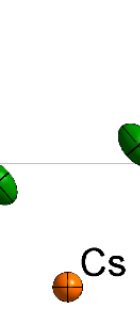

Cs 8

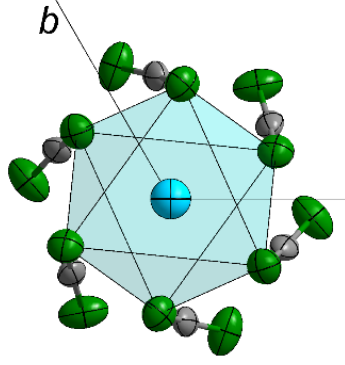

b)

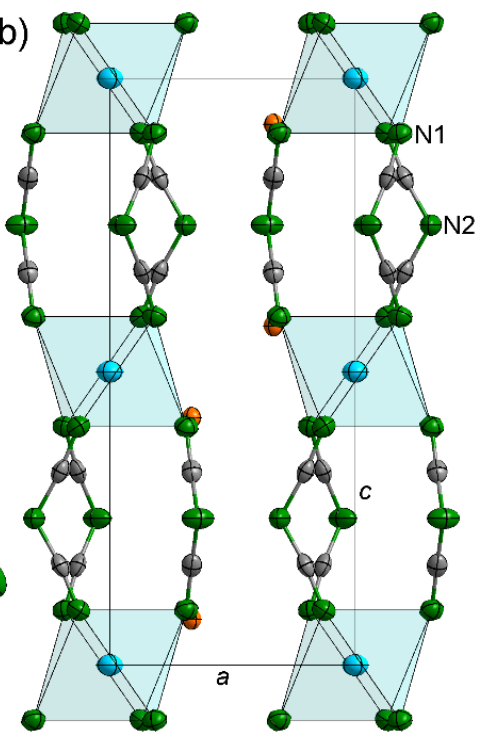

Figure 1. Crystal structure of $\mathrm{LiCs}_{2}[\mathrm{dca}]_{3}$ with (a) viewed along the $c$ axis and (b) along the $b$ axis. The thermal ellipsoids correspond to $90 \%$ probability using the refined ADPs.

Table 1. Selected bond lengths $(\AA)$ and angles $\left({ }^{\circ}\right)$ of $\mathrm{LiCs}_{2}\left[\mathrm{dca}_{3}\right.$ in comparison to $\mathrm{NaCs}_{2}[\mathrm{dca}]_{3}$.

\begin{tabular}{|c|c|c|c|}
\hline \multicolumn{2}{|l|}{$\mathrm{LiCs}_{2}[\mathrm{dca}]_{3}$} & \multicolumn{2}{|c|}{$\mathrm{NaCs}_{2}[\mathrm{dca}]_{3}[25]$} \\
\hline Li-N1 $(6 \times)$ & $2.2823(1)$ & $\mathrm{Na}-\mathrm{N} 1(6 \times)$ & $2.468(3)$ \\
\hline Cs-N2 $(3 \times)$ & $3.5225(2)$ & Cs-N2 $(3 \times)$ & $3.629(3)$ \\
\hline Cs-N1 $(3 \times)$ & $3.2289(2)$ & Cs-N1 $(3 \times)$ & $3.284(3)$ \\
\hline Cs-N1 $(3 \times)$ & $3.2473(2)$ & Cs-N1 $(3 \times)$ & $3.276(3)$ \\
\hline & & $\mathrm{Cs}-\mathrm{N} 1(3 \times)$ & $3.741(2)$ \\
\hline N1-C & $1.1647(1)$ & $\mathrm{N} 1-\mathrm{C}$ & $1.154(4)$ \\
\hline $\mathrm{N} 2-\mathrm{C}(2 \times)$ & $1.3133(1)$ & N2-C (2×) & $1.315(3)$ \\
\hline$\measuredangle(\mathrm{C}-\mathrm{N} 2-\mathrm{C})$ & 119.792(7) & $\measuredangle(\mathrm{C}-\mathrm{N} 2-\mathrm{C})$ & $119.5(2)$ \\
\hline$\measuredangle(\mathrm{N} 1-\mathrm{C}-\mathrm{N} 2)$ & $172.140(4)$ & $\measuredangle(\mathrm{N} 1-\mathrm{C}-\mathrm{N} 2)$ & $172.6(3)$ \\
\hline
\end{tabular}

$\mathrm{Li}^{+}$is octahedrally coordinated by six terminal nitrogen atoms of six different [dca] moieties with $d(\mathrm{Li}-\mathrm{N} 1)=2.28 \AA$. This distance is in good agreement with $\mathrm{Li}-\mathrm{N}$ distances for the octahedrally coordinated lithium cation in Li[dca] (2.22-2.29 $\AA$ ) [9]. These octahedra are connected with each other by sharing three $\left[\mathrm{N}(\mathrm{CN})_{2}\right]^{-}$and they are bonded by the terminal nitrogen atoms. In this way columns are formed parallel to the crystallographic $c$ axis. These columns are packed hexagonally, forming channels hosting the cesium cations (Figure 1).

$\mathrm{NaCs}_{2}[\mathrm{dca}]_{3}$ was reported to incorporate coordination spheres around cesium with twelve nitrogen atoms from nine [dca]-groups and with two different distances [25]. A closer look at the structure of $\mathrm{NaCs}_{2}[\mathrm{dca}]_{3}$ reveals that there are four different $d(\mathrm{Cs}-\mathrm{N})$ (Table 1). The calculated valence bond sum (VBS [26]) confirms that all twelve nitrogen atoms are part of the coordination sphere for $\mathrm{Cs}^{+}$in $\mathrm{NaCs}_{2}[\mathrm{dca}]_{3}$. This is not the case for the title compound. Calculations via VBS analysis reveals that the coordination sphere of $\mathrm{Cs}^{+}$contains nine nitrogen atoms of nine different dicyanamides with three different distances (Figure 2, Table 1), generating a tri-capped trigonal prism according to IUPAC nomenclature. Two cesium atoms share six of these groups. Half of these anions coordinate the $\mathrm{Cs}^{+}$ via their bridging nitrogen with $d(\mathrm{Cs}-\mathrm{N} 2=3.52 \AA)$; for the other half, it was found that six nitrogen atoms coordinate terminally to the cesium cation with $d(\mathrm{Cs}-\mathrm{N} 1=3.25 \AA)$. The coordination sphere is completed by three terminal nitrogen atoms in the layers below or above the $\mathrm{Cs}^{+}$with $d(\mathrm{Cs}-\mathrm{N} 1$ 
$=3.23 \AA$ ). These distances are in good agreement with Cs-N distances in Cs[dca] (3.26-3.62 ̊̊ with $\mathrm{CN}=10$ and 3.15-3.31 $\AA$ with $\mathrm{CN}=8)$ [12].

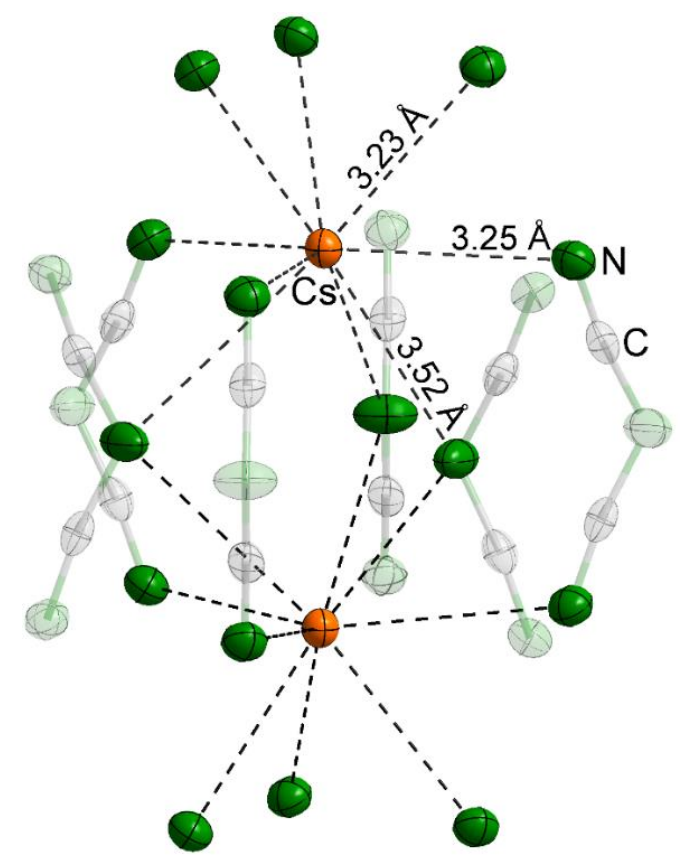

Figure 2. Coordination sphere of $\mathrm{Cs}$ in $\mathrm{LiCs}_{2}[\mathrm{dca}]_{3}$. Atoms not involved have been greyed out. The thermal ellipsoids correspond to $90 \%$ probability using the refined ADPs.

\subsection{Vibrational Spectra}

The frequencies obtained from the IR and Raman spectra of the title compound confirm the presence of the [dca] moiety and agree very well to the IR/Raman data of the isostructural $\mathrm{NaCs}_{2}\left[\mathrm{dca}_{3}\right.$ [25] (Figure 3, Table 2). The IR spectrum was measured under atmospheric conditions, therefore it shows the presence of water due the hygroscopic nature of the title compound.

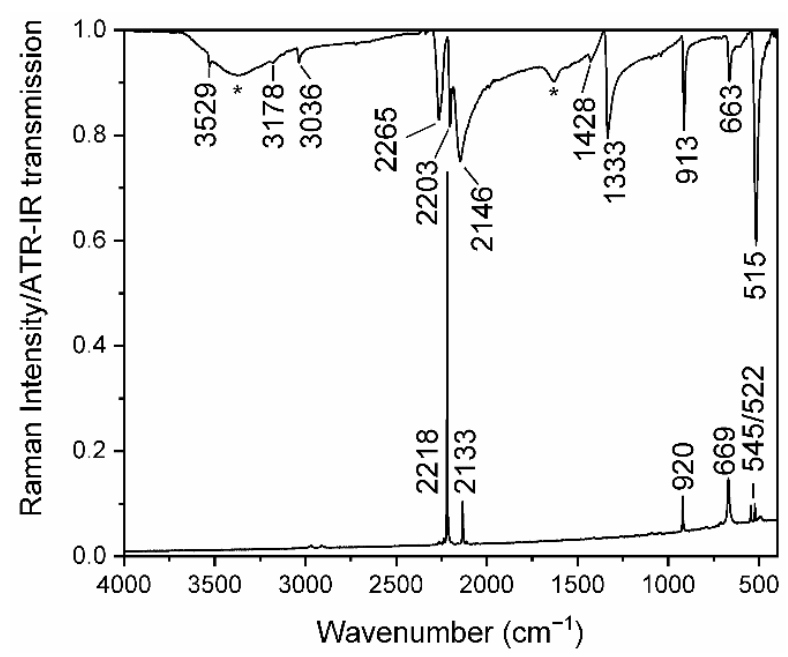

Figure 3. IR and Raman spectra of $\mathrm{LiCs}_{2}[\mathrm{dca}]_{3}$. The asterisks mark vibrations of water. 
Table 2. IR and Raman data of $\mathrm{LiCs}_{2}\left[\mathrm{dca}_{3}\right.$ in comparison to $\mathrm{NaCs}_{2}\left[\mathrm{dca}_{3}\right.$. All numbers are given in $\mathrm{cm}^{-1}$.

\begin{tabular}{|c|c|c|c|}
\hline & $\nu_{\mathrm{IR}}\left(\mathrm{LiCs}_{2}[\mathrm{dca}]_{3}\right)$ & $v_{\text {Raman }}\left(\operatorname{LiCs}_{2}\left[\mathrm{dca}_{3}\right)\right.$ & $v\left(\mathrm{NaCs}_{2}\left[\mathrm{dca}_{3}\right)[25]\right.$ \\
\hline$\sigma_{\mathrm{as}}(\mathrm{N}-\mathrm{C} \equiv \mathrm{N})$ & 515 & - & 516 \\
\hline$\gamma_{\text {as }}(\mathrm{N}-\mathrm{C} \equiv \mathrm{N})$ & - & 522 & 526 \\
\hline$\gamma_{\mathrm{s}}(\mathrm{N}-\mathrm{C} \equiv \mathrm{N})$ & - & 545 & 543 \\
\hline$\sigma_{\mathrm{S}}(\mathrm{N}-\mathrm{C} \equiv \mathrm{N})$ & 663 & 669 & 666 \\
\hline$v_{\mathrm{S}}(\mathrm{N}-\mathrm{C})$ & 913 & 920 & $930 / 917$ \\
\hline$\nu_{\mathrm{as}}(\mathrm{N}-\mathrm{C})$ & 1333 & - & 1342 \\
\hline$v_{\mathrm{s}}(\mathrm{N}-\mathrm{C})+\sigma_{\mathrm{s}}(\mathrm{N}-\mathrm{C} \equiv \mathrm{N})$ & 1428 & - & 1437 \\
\hline$v_{\mathrm{as}}(\mathrm{N} \equiv \mathrm{C})$ & 2146 & 2133 & 2167 \\
\hline$v_{\mathrm{as}}(\mathrm{N}-\mathrm{C})+v_{\mathrm{s}}(\mathrm{N}-\mathrm{C})$ & 2203 & 2218 & $2228 / 2206$ \\
\hline$v_{\mathrm{s}}(\mathrm{N} \equiv \mathrm{C})$ & 2265 & - & $2286 / 2267$ \\
\hline$v_{\mathrm{as}}(\mathrm{N} \equiv \mathrm{C})+v_{\mathrm{s}}(\mathrm{N}-\mathrm{C})$ & 3036 & - & 3061 \\
\hline$v_{\mathrm{S}}(\mathrm{N} \equiv \mathrm{C})+v_{\mathrm{s}}(\mathrm{N}-\mathrm{C})$ & 3178 & - & $3213 / 3179$ \\
\hline$v_{\mathrm{s}}(\mathrm{N} \equiv \mathrm{C})+v_{\mathrm{as}}(\mathrm{N}-\mathrm{C})$ & 3529 & - & $3549 / 3528 / 3471$ \\
\hline
\end{tabular}

\section{Materials and Methods}

\subsection{Synthesis}

All synthetic steps involving $\mathrm{AgNO}_{3}$ or $\mathrm{Ag}$ [dca] were carried out under exclusion of light. $\mathrm{Ag}$ [dca] was synthesized by mixing aqueous solutions of $\mathrm{Na}$ [dca] (974.45 mg, $10.95 \mathrm{mmol}$ in $10 \mathrm{~mL}$ ) and $\mathrm{AgNO}_{3}$ $(1965.26 \mathrm{mg}, 11.57 \mathrm{mmol}$ in $10 \mathrm{~mL})$. After $1 \mathrm{~h}$ of stirring, the white Ag[dca] (1827.96 mg, $10.51 \mathrm{mmol}$, yield $=96 \%$ ) was filtered off, washed with water, and dried under vacuum.

$\mathrm{LiCs}_{2}[\mathrm{dca}]_{3}$ was obtained by adding stoichiometric amounts of $\mathrm{CsBr}(382.89 \mathrm{mg}, 1.80 \mathrm{mmol})$ and $\mathrm{LiCl}$ (38.31 mg, $0.90 \mathrm{mmol})$ to an aqueous $\mathrm{Ag}[\mathrm{dca}]\left(472.06 \mathrm{mg}, 2.71 \mathrm{mmol}, 5 \mathrm{~mL} \mathrm{H} \mathrm{H}_{2} \mathrm{O}\right.$ ) suspension. The suspension was stirred for $12 \mathrm{~h}$. The solid silver halides were decanted off and $\mathrm{LiCs}_{2}\left[\mathrm{dca}_{3}\right.$ (314.37 mg, $0.722 \mathrm{mmol}$, yield $=79.9 \%$ compared to Ag[dca]) was obtained after water evaporation. Colorless, transparent crystals suitable for X-ray diffraction were selected and measured.

\subsection{Single-Crystal Diffraction}

Suitable single crystals were mounted on glass fibers. Intensity data were collected with a Bruker SMART APEX CCD detector (Bruker AXS GmbH, Karlsruhe, Germany) equipped with an Incoatec microsource (Mo-K $\alpha_{1}$ radiation, $\lambda=0.71073 \AA$, multilayer optics). Temperature control was achieved using an Oxford Cryostream 700 (Oxford Cryosystems Ltd, Oxford, United Kingdom) at $100 \mathrm{~K}$. Collected data were integrated with SAINT+ [27] and multi-scan absorption corrections were applied with $S A D A B S$ [28]. The structure was solved by charge-flipping methods (Superflip [29]) and refined on $F^{2}$ as implemented in Jana2006 [30]. More crystallographic details can be found in Tables 3-5 and in the supplementary materials. Additional details concerning the structure determination are available in CIF format and have been deposited under the CCDC entry number 1866007. Copies of the data can be obtained free of charge via http:/ / www.ccdc.cam.ac.uk/conts/retrieving.html (or from the CCDC, 12 Union Road, Cambridge CB2 1EZ, UK; Fax: +44 1223 336033; E-mail: deposit@ccdc.cam.ac.uk)

Table 3. Crystallographic data of $\mathrm{LiCs}_{2}[\mathrm{dca}]_{3}$.

\begin{tabular}{cc}
\hline Chemical Formula & LiCs $_{2}[\mathbf{d c a}]_{3}$ \\
\hline Formula weight $\left(\mathrm{g} \cdot \mathrm{mol}^{-1}\right)$ & 434.85 \\
Crystal system & hexagonal \\
Space group & $P 6_{3} / m$ (no. 176) \\
Temperature $(\mathrm{K})$ & 100 \\
$a(\AA)$ & $6.8480(8)$ \\
$c(\AA)$ & $14.1665(17)$ \\
$V\left(\AA^{3}\right)$ & $575.33(1)$ \\
\hline
\end{tabular}


Table 3. Cont.

\begin{tabular}{cc}
\hline$Z$ & 2 \\
Radiation, $\lambda(\AA)$ & Mo-K $\alpha_{1}, 0.71073$ \\
$\mu\left(\mathrm{mm}^{-1}\right)$ & 6.317 \\
Crystal shape and color & Colorless block \\
Crystal size $\left(\mathrm{mm}^{3}\right)$ & $0.02 \times 0.02 \times 0.03$ \\
$\rho_{\text {calc }}\left(\mathrm{g} \cdot \mathrm{cm}^{-3}\right)$ & 2.7181 \\
Diffractometer & Bruker APEX CCD \\
Absorption correction & Multi-scan, SADABS 2014/15 \\
$T_{\text {min }}, T_{\text {max }}$ & $0.5361,0.7461$ \\
No. of measured, independent and & $4655,617,528$ \\
observed $[I>3 \sigma(I)]$ reflections & 0.014 \\
$R_{\text {obs }}$ & 0.018 \\
$R_{\text {all }}$ & 1.07 \\
GOF & 30,0 \\
\hline
\end{tabular}

Table 4. Atomic coordinates and equivalent isotropic displacement parameters $U_{\mathrm{eq}}\left(\AA^{2}\right)$ of $\mathrm{LiCs}_{2}[\mathrm{dca}]_{3}$.

\begin{tabular}{cccccc}
\hline Atom & Site & $x$ & $y$ & $z$ & $U_{\text {eq }}$ \\
\hline $\mathrm{Li}$ & $2 b$ & 0 & 0 & 0 & $0.0144(17)$ \\
$\mathrm{Cs}$ & $4 f$ & $1 / 3$ & $2 / 2$ & $0.078375(12)$ & $0.00920(6)$ \\
$\mathrm{N} 2$ & $6 h$ & $0.3590(4)$ & $0.3077(4)$ & $1 / 4$ & $0.0155(9)$ \\
$\mathrm{N} 1$ & $12 i$ & $0.3115(2)$ & $0.1284(2)$ & $0.09385(11)$ & $0.0122(6)$ \\
$\mathrm{C}$ & $12 i$ & $0.3333(3)$ & $0.2014(3)$ & $0.16978(12)$ & $0.0098(6)$ \\
\hline
\end{tabular}

Table 5. Anisotropic displacement parameters $U_{\mathrm{ij}}\left(\AA^{2}\right)$ of $\mathrm{LiCs}_{2}[\mathrm{dca}]_{3}$.

\begin{tabular}{ccccccc}
\hline Atom & $\boldsymbol{U}_{\mathbf{1 1}}$ & $\boldsymbol{U}_{\mathbf{2 2}}$ & $\boldsymbol{U}_{\mathbf{3 3}}$ & $\boldsymbol{U}_{\mathbf{1 2}}$ & $\boldsymbol{U}_{\mathbf{1 3}}$ & $\boldsymbol{U}_{\mathbf{2 3}}$ \\
\hline $\mathrm{Li}$ & $0.016(2)$ & $0.016(2)$ & $0.010(3)$ & $0.0082(10)$ & 0 & 0 \\
$\mathrm{Cs}$ & $0.00892(8)$ & $0.00892(8)$ & $0.00975(10)$ & $0.00446(4)$ & 0 & 0 \\
$\mathrm{~N} 2$ & $0.0245(11)$ & $0.0113(10)$ & $0.0101(9)$ & $0.0084(10)$ & 0 & 0 \\
$\mathrm{~N} 1$ & $0.0134(7)$ & $0.0122(7)$ & $0.0107(7)$ & $0.0062(6)$ & $0.0005(5)$ & $0.0017(5)$ \\
$\mathrm{C}$ & $0.0089(7)$ & $0.0086(7)$ & $0.0128(8)$ & $0.0050(6)$ & $0.0006(6)$ & $0.0033(6)$ \\
\hline
\end{tabular}

\subsection{Infrared and Raman Spectra}

For the recording of the IR spectrum, an ALPHA II FT-IR-spectrometer (Bruker Optik $\mathrm{GmbH}$, Ettlingen, Germany) equipped with an ATR Platinum Diamond measuring cell was used. All measurements were performed within the range of 4000 to $400 \mathrm{~cm}^{-1}$.

Raman-spectroscopic investigations were performed on a microscope laser Raman spectrometer (Jobin Yvon, Unterhaching, Germany, $4 \mathrm{~mW}$, equipped with a HeNe laser with an excitation line at $\lambda=632.82 \mathrm{~nm}, 50 \times$ magnification, $2 \times 40 \mathrm{~s}$ accumulation time). The Raman spectrum was recorded on a crystal sealed in a thin-walled glass capillary.

\section{Conclusion}

The compound $\mathrm{LiCs}_{2}[\mathrm{dca}]_{3}$ was synthesized, its crystal structure determined, and its IR and Raman spectra were reported. The acquired data of the vibrational spectra as well as the structural results are similar to the data of the previously reported alkali metal dicyanamides $\mathrm{NaCs}_{2}\left[\mathrm{dca}_{3}\right.$, $\mathrm{Li}[\mathrm{dca}]$ and Cs[dca], although the smaller $\mathrm{Li}^{+}$changes the coordination of $\mathrm{Cs}^{+}$.

Supplementary Materials: The following are available online at http:/ /www.mdpi.com/2304-6740/6/4/108/s1: CIF and CIFchecked files.

Author Contributions: M.M. and O.R. conceived and designed the experiment; M.M. performed the synthesis, SXRD, and ATR-IR experiment; results were discussed with the assistance of O.R. and R.D.; and M.M. wrote the paper with the assistance of O.R. and R.D. 
Funding: This research received no external funding.

Acknowledgments: It is a pleasure to thank Armin Schulz (MPI-FKF, Stuttgart) for having measured the Raman spectrum.

Conflicts of Interest: The authors declare no conflict of interest.

\section{References}

1. Sougrati, M.T.; Darwiche, A.; Liu, X.; Mahmoud, A.; Hermann, R.P.; Jouen, S.; Monconduit, L.; Dronskowski, R.; Stievano, L. Transition-Metal Carbodiimides as Molecular Negative Electrode Materials for Lithium- and Sodium-Ion Batteries with Excellent Cycling Properties. Angew. Chem. Int. Ed. 2016, 55, 5090-5095. [CrossRef] [PubMed]

2. Sougrati, M.T.; Arayamparambil, J.J.; Liu, X.; Mann, M.; Slabon, A.; Stievano, L.; Dronskowski, R. Carbodiimides as energy materials: Which directions for a reasonable future? Dalton Trans. 2018, 47, 10827-10832. [CrossRef] [PubMed]

3. Scholz, T.; Görne, A.L.; Dronskowski, R. Itinerant nitrides and salt-like guanidinates-The diversity of solid-state nitrogen chemistry. Prog. Solid State Chem. 2018, 51, 1-18. [CrossRef]

4. Manson, J.L.; Kmety, C.R.; Huang, Q.-z.; Lynn, J.W.; Bendele, G.M.; Pagola, S.; Stephens, P.W.; Liable-Sands, L.M.; Rheingold, A.L.; Epstein, A.J.; et al. Structure and Magnetic Ordering of $\mathrm{M}^{\mathrm{II}}\left[\mathrm{N}(\mathrm{CN})_{2}\right]_{2}$ (M = Co, Ni). Chem. Mater. 1998, 10, 2552-2560. [CrossRef]

5. Raebiger, J.W.; Manson, J.L.; Sommer, R.D.; Geiser, U.; Rheingold, A.L.; Miller, J.S. 1-D and 2-D Homoleptic Dicyanamide Structures, $\left[\mathrm{Ph}_{4} \mathrm{P}\right]_{2}\left\{\mathrm{Co}{ }^{I}\left[\mathrm{~N}(\mathrm{CN})_{2}\right]_{4}\right\}$ and $\left[\mathrm{Ph}_{4} \mathrm{P}\right]\left\{\mathrm{M}\left[\mathrm{N}(\mathrm{CN})_{2}\right]_{3}\right\}(\mathrm{M}=\mathrm{Mn}, \mathrm{Co})$. Inorg. Chem. 2001, 40, 2578-2581. [CrossRef] [PubMed]

6. Nune, S.V.K.; Basaran, A.T.; Ülker, E.; Mishra, R.; Karadas, F. Metal Dicyanamides as Efficient and Robust Water-Oxidation Catalysts. Chem CatChem 2017, 9, 300-307. [CrossRef]

7. Yoon, H.; Lane, G.H.; Shekibi, Y.; Howlett, P.C.; Forsyth, M.; Best, A.S.; MacFarlane, D.R. Lithium electrochemistry and cycling behaviour of ionic liquids using cyano based anions. Energy Environ. Sci. 2013, 6, 979-986. [CrossRef]

8. Jürgens, B.; Höppe, H.A.; Irran, E.; Schnick, W. Transformation of Ammonium Dicyanamide into Dicyandiamide in the Solid. Inorg. Chem. 2002, 41, 4849-4851. [CrossRef] [PubMed]

9. Reckeweg, O.; DiSalvo, F.J.; Schulz, A.; Blaschkowski, B.; Jagiella, S.; Schleid, T. Synthesis, Crystal Structure, and Vibrational Spectra of the Anhydrous Lithium Dicyanamide $\mathrm{Li}\left[\mathrm{N}(\mathrm{CN})_{2}\right]$. Z. Anorg. Allg. Chem. 2014, 640, 851-855. [CrossRef]

10. Jürgens, B.; Irran, E.; Schneider, J.; Schnick, W. Trimerization of $\mathrm{NaC}_{2} \mathrm{~N}_{3}$ to $\mathrm{Na}_{3} \mathrm{C}_{6} \mathrm{~N}_{9}$ in the Solid: $\mathrm{Ab}$ Initio Crystal Structure Determination of Two Polymorphs of $\mathrm{NaC}_{2} \mathrm{~N}_{3}$ and of $\mathrm{Na}_{3} \mathrm{C}_{6} \mathrm{~N}_{9}$ from X-ray Powder Diffractometry. Inorg. Chem. 2000, 39, 665-670. [CrossRef] [PubMed]

11. Irran, E.; Jürgens, B.; Schnick, W. Trimerization of alkali dicyanamides $\mathrm{M}\left[\mathrm{N}(\mathrm{CN})_{2}\right]$ and formation of tricyanomelaminates $M_{3}\left[\mathrm{C}_{6} \mathrm{~N}_{9}\right](M=\mathrm{K}, \mathrm{Rb})$ in the melt: Crystal structure determination of three polymorphs of $\mathrm{K}\left[\mathrm{N}(\mathrm{CN})_{2}\right]$, two of $\mathrm{Rb}\left[\mathrm{N}(\mathrm{CN})_{2}\right]$, and one of $\mathrm{K}_{3}\left[\mathrm{C}_{6} \mathrm{~N}_{9}\right]$ and $\mathrm{Rb}_{3}\left[\mathrm{C}_{6} \mathrm{~N}_{9}\right]$ from X-ray powder diffractometry. Chem. Eur. J. 2001, 7, 5372-5381. [CrossRef] [PubMed]

12. Starynowicz, P. Structure of caesium dicyanamide. Acta Crystallogr. Sect. C 1991, 47, 2198-2199. [CrossRef]

13. Jürgens, B.; Irran, E.; Schnick, W. Syntheses, Vibrational Spectroscopy, and Crystal Structure Determination from X-Ray Powder Diffraction Data of Alkaline Earth Dicyanamides $M\left[\mathrm{~N}(\mathrm{CN})_{2}\right]_{2}$ with $M=\mathrm{Mg}$, Ca, Sr, and Ba. J. Solid State Chem. 2001, 157, 241-249. [CrossRef]

14. Manson, J.L.; Kmety, C.R.; Epstein, A.J.; Miller, J.S. Spontaneous Magnetization in the $M\left[N(C N)_{2}\right]_{2}(M=C r$, $\mathrm{Mn})$ Weak Ferromagnets. Inorg. Chem. 1999, 38, 2552-2553. [CrossRef]

15. Hodgson, S.A.; Hunt, S.J.; Sørensen, T.J.; Thompson, A.L.; Reynolds, E.M.; Faulkner, S.; Goodwin, A.L. Anomalous Thermal Expansion and Luminescence Thermochromism in Silver(I) Dicyanamide. Eur. J. Inorg. Chem. 2016, 2016, 4378-4381. [CrossRef]

16. Reckeweg, O.; Schulz, A.; Schneck, C.; Lissner, F.; Schleid, T. Syntheses, single-crystal structures, vibrational spectra and DSC/TG analyses of orthorhombic and trigonal $\mathrm{Ag}\left[\mathrm{N}(\mathrm{CN})_{2}\right]$. Z. Naturforsch. B 2016, 71, 827-834. [CrossRef] 
17. Jürgens, B.; Irran, E.; Höppe, H.A.; Schnick, W. Phase Transition of a Dicyanamide with Rutile-like Structure: Syntheses and Crystal Structures of $\alpha$ - and $\beta-\mathrm{Cd}\left[\mathrm{N}(\mathrm{CN})_{2}\right]_{2}$. Z. Anorg. Allg. Chem. 2004, 630, 219-223. [CrossRef]

18. Reckeweg, O.; Dinnebier, R.E.; Schulz, A.; Blaschkowski, B.; Schneck, C.; Schleid, T. About the air- and water-stable copper(I) dicyanamide: Synthesis, crystal structure, vibrational spectra and DSC/TG analysis of $\mathrm{Cu}\left[\mathrm{N}(\mathrm{CN})_{2}\right.$ ]. Z. Naturforsch, B 2017, 72, 159-165. [CrossRef]

19. Manson, J.L.; Lee, D.W.; Rheingold, A.L.; Miller, J.S. Buckled-layered Structure of Zinc Dicyanamide, $\mathrm{Zn}{ }^{\mathrm{II}}\left[\mathrm{N}(\mathrm{CN})_{2}\right]_{2}$. Inorg. Chem. 1998, 37, 5966-5967. [CrossRef] [PubMed]

20. Jürgens, B.; Irran, E.; Schnick, W. Synthesis and characterization of the rare-earth dicyanamides $\operatorname{Ln}\left[\mathrm{N}(\mathrm{CN})_{2}\right]_{3}$ with Ln = La, Ce, Pr, Nd, Sm, and Eu. J. Solid State Chem. 2005, 178, 72-78. [CrossRef]

21. Nag, A.; Schnick, W. Synthesis, Crystal Structure and Thermal Behavior of Gadolinium Dicyanamide Dihydrate $\mathrm{Gd}\left[\mathrm{N}(\mathrm{CN})_{2}\right]_{3} \cdot 2 \mathrm{H}_{2} \mathrm{O}$. Z. Anorg. Allg. Chem. 2006, 632, 609-614. [CrossRef]

22. Nag, A.; Schmidt, P.J.; Schnick, W. Synthesis and Characterization of $\mathrm{Tb}\left[\mathrm{N}(\mathrm{CN})_{2}\right]_{3} \cdot 2 \mathrm{H}_{2} \mathrm{O}$ and $\mathrm{Eu}\left[\mathrm{N}(\mathrm{CN})_{2}\right]_{3} \cdot 2 \mathrm{H}_{2} \mathrm{O}$ : Two New Luminescent Rare-Earth Dicyanamides. Chem. Mater. 2006, 18, 5738-5745. [CrossRef]

23. Reckeweg, O.; Wakabayashi, R.H.; DiSalvo, F.J.; Schulz, A.; Schneck, C.; Schleid, T. About alkali metal dicyanamides: Syntheses, single-crystal structure determination, DSC/TG and vibrational spectra of $\mathrm{KCs}\left[\mathrm{N}(\mathrm{CN})_{2}\right]_{2}$ and $\mathrm{NaRb}_{2}\left[\mathrm{~N}(\mathrm{CN})_{2}\right]_{3} \cdot \mathrm{H}_{2} \mathrm{O}$. Z. Naturforsch. B 2015, 70, 365-372. [CrossRef]

24. Reckeweg, O.; DiSalvo, F.J. Synthesis and single-crystal structure of the pseudo-ternary compounds $\mathrm{Li} A\left[\mathrm{~N}(\mathrm{CN})_{2}\right]_{2}(A=\mathrm{K}$ or Rb). Z. Naturforsch. B 2016, 71, 157-160. [CrossRef]

25. Jürgens, B.; Milius, W.; Morys, P.; Schnick, W. Trimerisierung von Dicyanamid-Ionen $\mathrm{C}_{2} \mathrm{~N}_{3}-\mathrm{im}$ Festkörper-Synthesen, Kristallstrukturen und Eigenschaften von $\mathrm{NaCs}_{2}\left(\mathrm{C}_{2} \mathrm{~N}_{3}\right)_{3}$ und $\mathrm{Na}_{3} \mathrm{C}_{6} \mathrm{~N}_{9} \cdot 3 \mathrm{H}_{2} \mathrm{O}$. Z. Anorg. Allg. Chem. 1998, 624, 91-97. [CrossRef]

26. Brese, N.E.; O’Keeffe, M. Bond-valence parameters for solids. Acta Crystallogr. Sect. B 1991, 47, $192-197$. [CrossRef]

27. Bruker AXS Inc. SAINT Version 7.68A; Bruker AXS Inc.: Madison, WI, USA, 2009.

28. Bruker AXS Inc. SADABS Version 2004/1; Bruker AXS Inc.: Madison, WI, USA, 2004.

29. Palatinus, L.; Chapuis, G. SUPERFLIP-A computer program for the solution of crystal structures by charge flipping in arbitrary dimensions. J. Appl. Crystallogr. 2007, 40, 786-790. [CrossRef]

30. Petříček, V.; Dušek, M.; Palatinus, L. Crystallographic Computing System JANA2006: General features. Z. Kristallogr. Cryst. Mater. 2014, 229, 345-352. [CrossRef] 